\title{
Acetylcholinesterase and Butyrylcholinesterase Genes Coamplify in Primary Ovarian Carcinomas
}

\author{
Haim Zakut, ${ }^{\star}$ Gal Ehrlich, ${ }^{\ddagger}$ Ari Ayalon, ${ }^{\star \star}$ Catherine A. Prody, ${ }^{\ddagger}$ Gustavo Malinger, ${ }^{\star *}$ \\ Shlomo Seidman, ${ }^{\ddagger}$ Dalia Ginzberg, ${ }^{\ddagger}$ Ralph Kehlenbach, ${ }^{\ddagger}$ and Hermona Soreq ${ }^{\ddagger}$ \\ ${ }^{*}$ Department of Obstetrics and Gynecology, The Edith Wolfson Medical Center Holon, The Sackler Faculty of Medicine of the Tel Aviv \\ University; and the ${ }^{\ddagger}$ Department of Biological Chemistry, The Life Sciences Institute, The Hebrew University, Jerusalem, Israel
}

\begin{abstract}
The genes for acetylcholinesterase (ACHE) and butyrylcholinesterase (CHE) are expressed in multiple tumor tissues, including ovarian carcinomas. Both CHE and ACHE genes coamplify in leukemias. To examine the relationship of gene amplification to the expression of these genes in tumors, ACHE and CHE genes and their expression were studied in primary ovarian carcinomas. DNA blot hybridization demonstrated a significant amplification and mutagenesis of both genes in 6 of 11 malignant tumors studied. This was greater or of the same order of magnitude as the amplification of the oncogenes c-rafi, v-sis, and c-fes in these tumors. No amplifcation was found in normal ovarian tissues or benign ovarian cysts. Xenopus oocyte microinjections, blot and in situ hybridizations, and immuno- and cytochemical staining revealed translatable CHEmRNA and its active protein product in discrete tumor foci. The frequent coamplification in ovarian carcinomas of ACHE and CHE genes implicates cholinesterases in neoplastic growth and/or proliferation. (J. Clin. Invest. 1990. 86:900-908.) Key words: cytochemical staining • immunofluorescence $\bullet$ oncogenes coamplification - Xenopus oocyte bioassay $\bullet$ in situ hybridization
\end{abstract}

\section{Introduction}

The ubiquitous enzyme family of cholinesterases includes two members for which human cDNA probes have been isolated, permitting studies at the genomic level. These are acetylcholinesterase (acetylcholine acetylhydrolase, EC 3.1.1.7, ACHE) ${ }^{1}$ (1) and butyrylcholinesterase (acylcholine acylhydrolase, EC 3.1.1.8, CHE [2, 3]). Both enzymes can hydrolyze the neurotransmitter acetylcholine $(4,5)$ and both may be found in large amounts in various embryonic and tumor tissues (6), concomitant with cell division and DNA synthesis (7). Using the re-

Presented in abstract form at the Annual Meeting of the Israel Society of Medical Genetics, November 1989.

Address reprint requests to Dr. Zakut, The Edith Wolfson Medical Center, Box 5, Holon, 58100, Israel.

Received for publication 24 January 1990 and in revised form 20 March 1990.

1. Abbreviations used in this paper: ACHE, acetylcholinesterase; BW284C51, 1,5-bis(4-allyldimethylammoniumphenyl)-pentan-3-one dibromide; CHE, butyrylcholinesterase; iso-OMPA, tetra isopropylpyrophosphoramide; PCR, polymerase chain reaction.

J. Clin. Invest.

(c) The American Society for Clinical Investigation, Inc.

0021-9738/90/09/0900/09 \$2.00

Volume 86, September 1990, 900-908 cently cloned human ACHEcDNA (1) and CHEcDNA (2), we found that the $\mathrm{CHE}$ gene is capable of being heritably amplified in humans (8). Further analysis revealed the occurrence of coamplified ACHEDNA and CHEDNA sequences in genomic DNA from peripheral blood cells of leukemic patients (9). Altogether, these findings raised the question whether the previously reported high level of expression of the ACHE and CHE enzymes in tumors $(10,11)$ is effected by gene amplification. The rapidly progressing carcinomas of the ovary (12) offer a promising model in which to test this possibility since sections from these tumors exhibit pronounced diffuse cytochemical staining of $\mathrm{CHE}$ activities (10), whereas CHE expression in normal ovarian tissue appears to be confined to maturing oocytes $(13,14)$. Here we demonstrate that both the $\mathrm{ACHE}$ and $\mathrm{CHE}$ genes are amplified in primary ovarian carcinomas, and are expressed in dividing cells within tumor foci, implicating cholinesterases in tumor growth and development.

\section{Methods}

Primary tumor samples. Specimens of primary tumors were obtained at surgery, frozen immediately in liquid nitrogen and stored at $-70^{\circ} \mathrm{C}$ until used. Tumor subclassification was performed by standard pathological techniques. Tumor DNA (13) and poly(A)+RNA (15) were prepared as previously detailed.

cDNA oligonucleotide primers, and plasmid probes. ACHEcDNA and CHEcDNA probes were enzymatically excised, electrophoretically eluted and precipitated as previously reported (9). The c-rafi plasmid was from Amersham Corp. (Arlington Heights, IL). v-sis, c-fes, and c-myc (third exon) DNA probes were gratefully received from Opher Gileadi (The Hebrew University, Jerusalem). Oligonucleotide primers complementary to CHEcDNA were according to Soreq and Gnatt (16) and others (17). Polymerase chain reactions (PCR) were performed with Taq polymerase (BioLabs) according to published procedures (for example, see reference 17 ).

Blot and in situ hybridization. ${ }^{32} \mathrm{P}$ and ${ }^{35} \mathrm{~S}$-labeled cDNA and plasmid probes were labeled by the multi-prime labeling method (Boehringer Mannheim Biochemicals, Indianapolis, IN) to specific activities of $1-5 \times 109 \mathrm{dpm} / \mu \mathrm{g}$ DNA using enzymatically restricted and gel electroeluted DNA fragments $(2,8)$. DNA $(9)$ and RNA (2) blot hybridizations were performed as previously described, and washes were at $65^{\circ} \mathrm{C}$ at low ionic strength $(0.1 \times \mathrm{SSC})$. In situ hybridization with $\left[{ }^{35} \mathrm{~S}\right] \mathrm{CHECDNA}$ and $\left[{ }^{35} \mathrm{~S}\right] \mathrm{ACHECDNA}$ probes was done with consecutive $10-\mu \mathrm{m}$ thick cryostat sections from the above tumor samples as detailed $(13,14)$. Immunocytochemical staining was done with the AE-2 monoclonal anti-ACHE antibodies, which cross-react with CHE (8). Cytochemical staining of cholinesterase activities was performed by the acetylthiocholine method as detailed elsewhere (19).

Xenopus oocytes microinjection. Oocytes were injected in groups of 30 , with $50 \mathrm{ng}$ of poly(A)+RNA from primary ovarian carcinomas in $50 \mathrm{nl} \mathrm{H}_{2} \mathrm{O}$ per oocyte, or with $50 \mathrm{nl}$ of Barth medium for controls (15, 20). Oocyte incubation was $18 \mathrm{~h}$ at $19^{\circ} \mathrm{C}$ in Barth medium. Incubated oocytes were homogenized and processed for biochemical determination of cholinesterase activities. Enzymatic assays were performed for 
$48 \mathrm{~h}$ at $21^{\circ} \mathrm{C}$. Data represent average values of three determinations (altogether 90 oocytes for each mRNA preparation) with up to $20 \%$ deviation between experiments.

Enzymatic activity measurements. Cholinesterase activities were measured spectrophotometrically by monitoring the hydrolysis of acetyl- or butyrylthiocholine in the presence of 5,5'-dithiobis(2-nitrobenzoic acid) as previously described $(18,20)$. Alternatively, we used the radioactive assay by measuring the release of $\left[{ }^{3} \mathrm{H}\right]$ acetate from acetylcholine (15). In both cases, 5-10- $\mu$ l samples of 1:10 (weight per volume) tissue or oocyte homogenates in PBS (the equivalent of $\sim 1 \mu \mathrm{g}$ tissue or one-half oocyte) were assayed at room temperature. Rates of spontaneous substrate hydrolysis were calculated, averaged and subtracted in both cases. Either 10-5 M 1,5-bis-(4-allyldimethylammoniumphenyl)-pentan-3-one dibromide (BW284C51, ACHE specific) or 10-5 M tetra-isopropylpyrophosphoramide (iso-OMPA, CHE specific) were used for selective inhibition experiments. iso-OMPA was preincubated with the samples $40 \mathrm{~min}$ before the addition of substrate to ensure complete irreversible binding. Protein determinations were by the Bradford technique, as previously detailed (15).

\section{Results}

When DNA from untreated primary ovarian carcinomas was subjected to restriction enzyme digestion and blot hybridization with $\left[{ }^{32} \mathrm{P}\right] \mathrm{ACHECDNA}$ and $\left[{ }^{32} \mathrm{P}\right] \mathrm{CHEcDNA}$, amplified hybridization signals were clearly observed with both probes in 6 of 11 malignant tumors, but not in benign ovarian tissues (Fig. 1). In each case of amplification, novel bands were observed in addition to those representing the normal ACHE and CHE genes. The two nonhomologous cDNA probes, which were previously shown not to cross-hybridize under the hybridization conditions employed (9) appeared to colabel novel restriction fragments of the same size when cut with both of the restriction enzymes Eco RI and Rsa I, in DNA samples having the coamplification and under exposure conditions where the normal genes were hardly detectable. In contrast, no fragments of this size were found in DNA samples with normal $\mathrm{ACHE}$ and $\mathrm{CHE}$ genes (Fig. 1). It is interesting that the amplified CHEDNA sequences appeared not to include the internal Hind III restriction site characteristic of the normal, introncontaining CHE gene (17, 21) (Fig. 2). Furthermore, Taq I generated two major fragments of 1400 and 600 basepairs from amplified CHE genes in each of these tumors, similarly with processed, intron-less CHEcDNA that includes such Taq I sites $(2,3)$ (Fig. 2, $(A$ and $B)$. To examine whether the abnormal restriction patterns reflected reproducible mutagenesis or processed $\mathrm{CHE}$ genes, PCR was performed. For this purpose, oligonucleotide primers were employed from several exon regions as well as across splice sites in the normal CHE gene (see reference 16 for detailed lists of CHEcDNA oligonucleotides and reference 21 for gene map). Both processed CHEcDNA and exon regions from the CHE genes in tumor DNA samples were faithfully amplified. In contrast, we failed to amplify the tumor CHE genes across splice sites, indicating that the amplified CHEDNA included large introns at the expected sites (not shown) and excluding the possibility that it had been inserted into the tumor DNA in processed, intron-free form.

The extent of ACHE and CHE gene amplifications in the tumors was determined by subjecting tumor DNAs to dot blot hybridization with [ $\left.{ }^{32} \mathrm{P}\right] \mathrm{ACHECDNA}$ and $\left[{ }^{32} \mathrm{P}\right] \mathrm{CHECDNA}$ followed by autoradiography and densitometric analysis. (Table I and Fig. 3). The aforementioned DNA samples from six malignant ovarian tumors included 7-23 pg of ACHEDNA

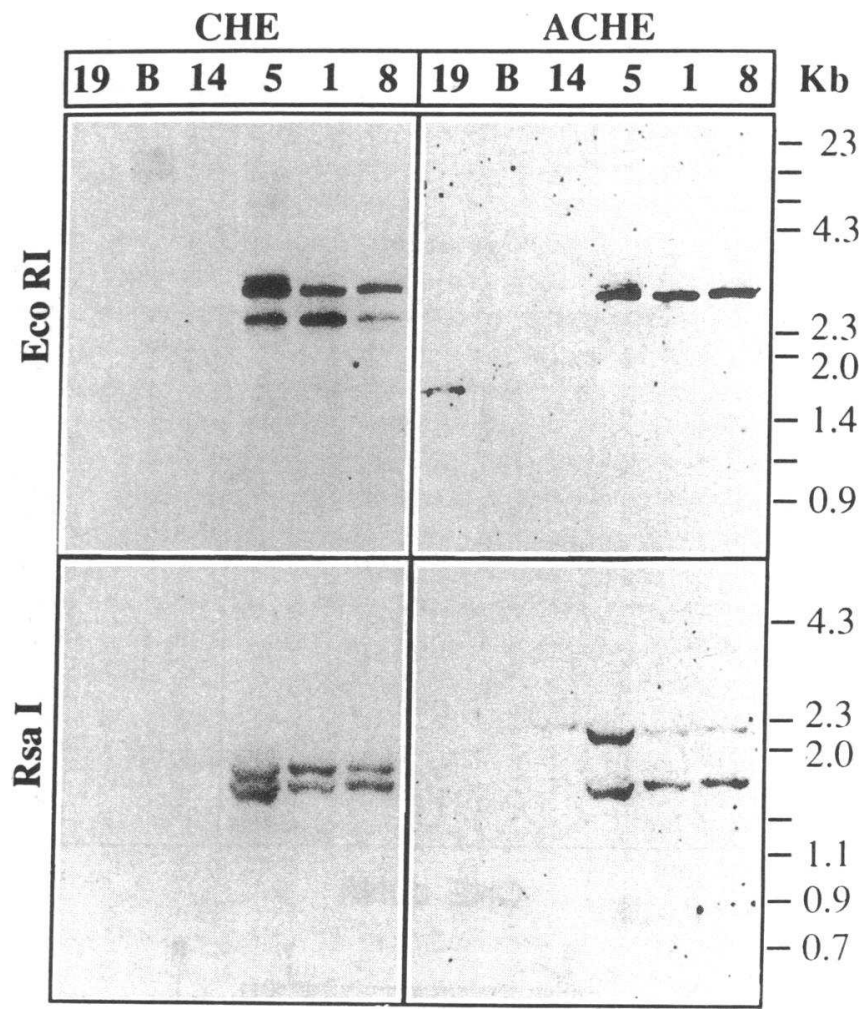

Figure 1. Co-amplification of the ACHE and CHE genes in primary ovarian carcinomas. $(A) 10-\mu \mathrm{g}$ samples of DNA from three primary ovarian carcinomas (Nos. 1, 5 and 8, Table I), 1 benign ovary (No. 19 , Table I) from a patient with a unilateral ovarian tumor and 1 brain DNA sample from an apparently normal individual $(B)$ were subjected to complete enzymatic digestion with the enzymes Eco RI or Rsa I, followed by agarose gel electrophoresis and DNA blot hybridization with a 1.5-kb long [ $\left.{ }^{32} \mathrm{P}\right] \mathrm{ACHECDNA}$ probe (1) or with a 2.4-kb long $\left.{ }^{32} \mathrm{P}\right] \mathrm{CHEcDNA}$ probe (2). Experimental details were according to previous publications $(8,9)$, and washing of filters was at $65^{\circ} \mathrm{C}$ in $0.1 \times$ SSC. Ethidium bromide staining of the agarose gels was employed to ascertain that equal amounts of DNA were loaded and electrophoretically separated in each of the lanes. Exposure was for $10 \mathrm{~d}$ at $-70^{\circ} \mathrm{C}$ with an intensifying screen. Hind III digested DNA from lambda phage and Hae III digested DNA from $\Phi \times 174$ phage served as molecular weight markers. Internal Rsa I restriction sites were found in both of these probes, whereas an Eco RI site exists in CHEcDNA but not in the ACHEcDNA probe employed. Note the intense hybridization signals, reflecting gene amplifications, with both those probes, which were shown to be non-cross-reactive with each other (9).

and 20-60 pg CHEDNA/ $\mu$ g genomic DNA, whereas DNA samples from four healthy control tissues and five benign tumors that were thus examined were found to include ACHEDNA and CHEDNA sequences equivalent to 1-7 pg of ACHEcDNA and CHEcDNA per $\mu \mathrm{g}$ (Fig. 3, Table I). These data reflect up to 10- or more fold amplification of the ACHE and the $\mathrm{CHE}$ genes in those ovarian tumors. Hybridization with regional CHEcDNA probes (8) indicated that the amplified DNA included the entire CHE coding sequence (not shown). Parallel hybridizations with cDNA probes from four different oncogenes revealed pronounced amplifications of the protein kinase oncogenes c-rafi and c-fes as well as the growth-factor oncogenes $\mathrm{v}$-sis in three of the six tumors having 


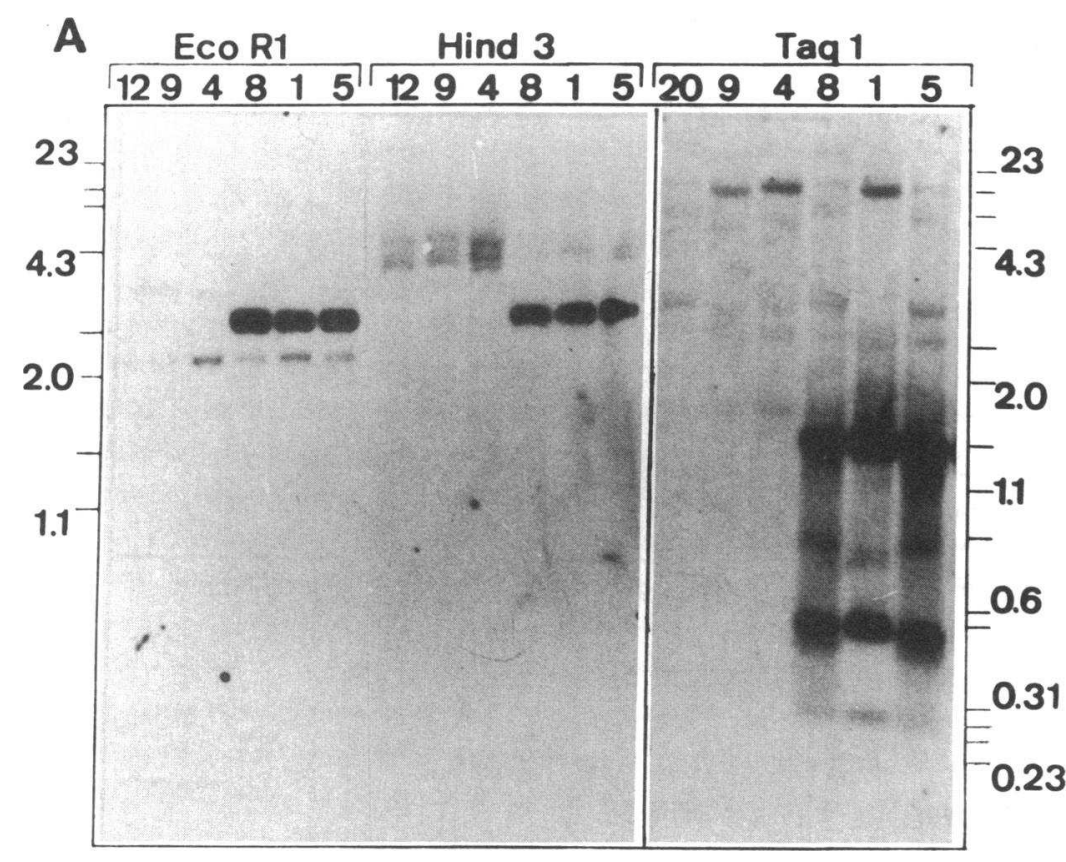

B CHE CDNA

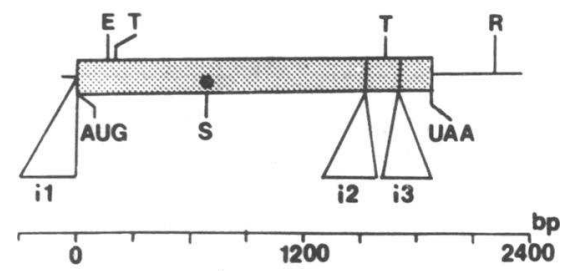

C

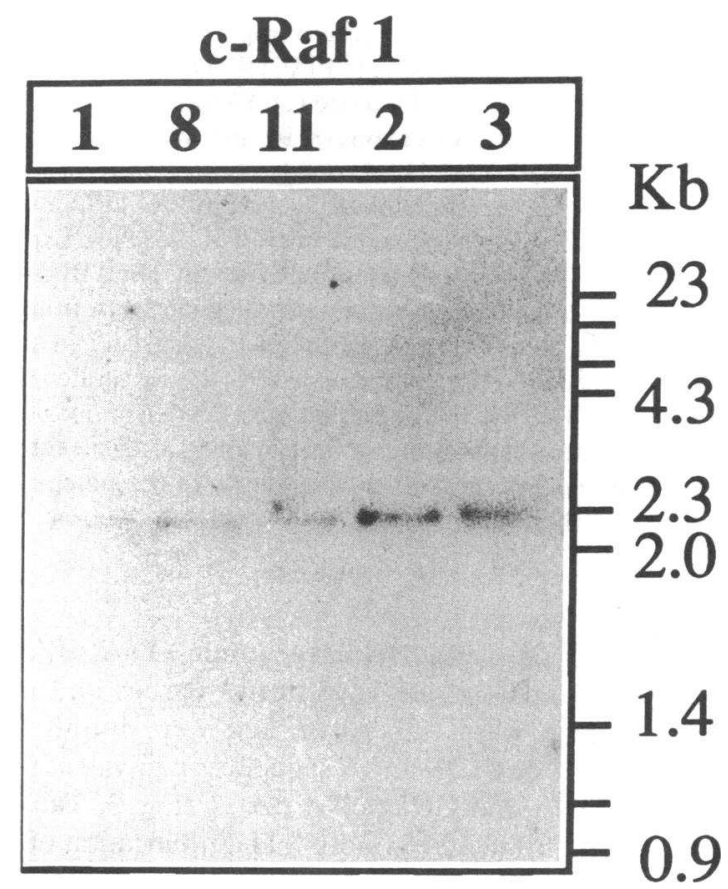

Figure 2. DNA blot hybridization reveals structural alterations in the amplified CHE genes in ovarian carcinomas. (A) 10- $\mu \mathrm{g}$ samples of DNA from five ovarian carcinomas (Nos. 1, 4, 5, 8 and 9, Table I) and 1 peripheral blood sample from a healthy individual (Sample No. 20, see Table I and reference 8 for details) were subjected to complete enzymatic digestion with the enzymes Hind III, Eco RI and Taq I, followed by agarose gel electrophoresis and DNA blot hybridization with [ $\left.{ }^{32} \mathrm{P}\right] \mathrm{CHECDNA}(2)$. Experimental details were similar to those of Fig. 1. Note the low intensity signal obtained with the normal CHE gene (No. 20), and the reproducibly altered structure of the amplified CHEDNA fragments. (B) Restriction site mapping of CHEcDNA (2) was performed with the enzymes Eco RI $(E)$; Taq I $(T)$ and Rsa I $(R)$. Initiation (AUG) and termination (UAA) sites are noted. The position of the three introns (il-3) in the human $\mathrm{CHE}$ gene was determined by analysis of genomic clones $(16,17)$. (A) $n=3^{\prime}$-poly(A) tail. The coding sequence is represented by shaded area. $(C)$ To ascertain the specificity of hybridization, used DNA blots were rehybridized with a plasmid DNA probe from the c-rafi protooncogene (Amersham Corp.), which also detected amplified DNA sequences in these primary tumors (Table I). This probe labeled a single, different band in all of the tumors, confirming that the hybridization signals with the ACHECDNA and CHEDNA probe indeed reflected the true amplification of genuine genomic sequences and were not due to plasmid DNA contaminations.
ACHE and/or CHE gene amplifications. It is of interest that these were the tumors with higher levels of amplified ACHEDNA and CHEDNA sequences and higher ratios between CHE:ACHE gene amplifications. No amplification in the third exon from c-myc, a nuclear protein oncogene was observed in any of these primary tumors. There was no apparent correlation between any of these gene amplifications and patient age. 


\begin{tabular}{|c|c|c|c|c|c|c|c|c|c|c|c|}
\hline \multirow[b]{5}{*}{ No. } & \multirow[b]{5}{*}{ Tumor classification and age } & \multicolumn{4}{|c|}{ Enzyme activities } & \multirow{4}{*}{\multicolumn{6}{|c|}{ Amplified genes $(p g / \mu g D N A)$}} \\
\hline & & \multirow{2}{*}{\multicolumn{2}{|c|}{ ACHE }} & \multirow{2}{*}{\multicolumn{2}{|c|}{$\mathrm{CHE}$}} & & & & & & \\
\hline & & & & & & & & & & & \\
\hline & & & Membrane & & Membrane & & & & & & \\
\hline & & Soluble & associated & Soluble & associated & CHE & ACHE & RAF1 & SIS & FES & MYC \\
\hline \multicolumn{12}{|c|}{ A. Malignant ovarian tumors } \\
\hline 1 & Serous papillary ad.ca (57) & 657 & 251 & 381 & 28 & $32-38$ & 4-6 & $40-50$ & $20-30$ & $10-12$ & $1-2$ \\
\hline 2 & Serous papillary ad.ca (54) & 105 & 27 & 119 & 17 & $21-26$ & $10-13$ & $2-3$ & $1-2$ & $1-2$ & $1-2$ \\
\hline 3 & Serous papillary ad.ca (22) & 980 & 183 & 412 & 33 & $20-24$ & $8-12$ & $2-3$ & $1-2$ & $1-2$ & $1-2$ \\
\hline 4 & Serous papillary ad.ca (55) & 607 & 218 & 397 & 31 & $7-11$ & ND & ND & ND & ND & ND \\
\hline 5 & Nondifferentiated ad.ca (44) & 1005 & 124 & 192 & 14 & $50-60$ & $7-11$ & $60-80$ & $40-50$ & $40-60$ & $2-3$ \\
\hline 6 & Nondifferentiated ad.ca (49) & 283 & 85 & 203 & 13 & $6-8$ & $4-6$ & $3-4$ & $1-2$ & $1-2$ & $1-2$ \\
\hline 7 & Nondifferentiated ad.ca (67) & 207 & 58 & 183 & 11 & $4-6$ & $6-8$ & $5-8$ & $20-30$ & $1-2$ & $1-2$ \\
\hline 8 & Endometrioid ad.ca (43) & 451 & 18 & 219 & 10 & $30-40$ & $9-12$ & $60-80$ & $40-50$ & $10-12$ & $2-3$ \\
\hline 9 & Endometrioid ad.ca (52) & 311 & 85 & 197 & 11 & $6-9$ & ND & ND & ND & ND & ND \\
\hline 10 & Moucinous ad.ca (87) & 193 & 81 & 128 & 7 & $5-10$ & ND & ND & ND & ND & ND \\
\hline 11 & Granulosa cell tumor (42) & 428 & 203 & 212 & 5 & $40-50$ & $18-23$ & $5-8$ & $1-3$ & $1-2$ & $1-2$ \\
\hline \multicolumn{12}{|c|}{ B. Benign ovarian tumors } \\
\hline 12 & Follicular cyst (47) & 208 & 53 & 211 & 6 & $5-7$ & ND & ND & ND & ND & ND \\
\hline 13 & Follicular cyst (48) & 412 & 183 & 222 & 5 & ND & ND & ND & ND & ND & ND \\
\hline 14 & Follicular cyst (46) & 298 & 89 & 232 & 4 & $5-7$ & ND & ND & ND & ND & ND \\
\hline 15 & Follicular cyst (36) & 753 & 412 & 361 & 6 & $5-7$ & ND & ND & ND & ND & ND \\
\hline 16 & Dermoid cyst (35) & 818 & 453 & 377 & 37 & $5-7$ & ND & ND & ND & ND & ND \\
\hline \multicolumn{12}{|c|}{ C. Others } \\
\hline 17 & Normal ovary (Uterine & & & & & & & & & & \\
\hline & myoma) (48) & 213 & 89 & 106 & 4 & $2-5$ & ND & ND & ND & ND & ND \\
\hline \multirow[t]{2}{*}{18} & Normal ovary (Uterine & & & & & & & & & & \\
\hline & myoma) (47) & 187 & 45 & 123 & 4 & $1-3$ & ND & ND & ND & ND & ND \\
\hline 19 & Benign ovary of No. 6 (49) & 192 & 35 & 138 & 5 & $3-7$ & $4-6$ & $5-8$ & $5-10$ & $3-4$ & $1-2$ \\
\hline \multirow[t]{2}{*}{20} & Peripheral blood, (no & & & & & & & & & & \\
\hline & pathologies) (37) & NA & NA & NA & NA & $1-3$ & $1-3$ & ND & ND & ND & NA \\
\hline
\end{tabular}

(A) DNA was extracted from 11 primary ovarian carcinoma tumors clinically classified as noted, before any treatment (ad.ca:adenocarcinoma); from five benign ovarian tumors and from four other tissue sources, as noted. (See reference 12 for detailed classification of ovarian carcinomas.) (B) ACHE and CHE activities, in nanomoles of acetylthiocholine and butyrylthiocholine hydrolyzed per minute per gram of tissue, were determined radiometrically or spectrophotometrically as detailed elsewhere $(8,15,20)$. Subcellular fractionation to soluble and membrane-associated fractions was performed as described (22). Spectrophotometric assays were performed in multiwell plates and five to six time points were measured in a Bio-Tek EL-309 microplate reader. Radioactivity measurements were performed in triplicates. Spontaneous hydrolysis of substrate was subtracted in both cases, and rates of enzymatic activity were calculated by linear regression analysis. The selective ACHE inhibitor BW284C51 and the CHE inhibitor iso-OMPA were both used in final concentration of 10-5 M to distinguish between ACHE and CHE activities, as detailed previously (11). (C) The approximate extent of ACHE and CHE gene amplification, as well as the amplification of c-rafi, c-fes, v-sis, and c-myc oncogenes was determined by dot-blot DNA hybridization followed by optical densitometry. Quantities of the labeled ACHEcDNA and CHEcDNA or oncogene DNA probes that hybridized with genomic corresponding DNA sequences in each tissue sample are presented in values equivalent to picogram of the relevant cDNA per microgram of genomic DNA. Measurements of ACHE and CHE gene quantification in peripheral blood DNA samples were performed as described (9) and compared to parallel levels determined in a healthy control (sample No. 20). Both the level and the DNA blot hybridization patterns of the ACHE and the CHE genes were similar in control blood DNA to those observed for DNA from normal ovary (sample 17 and reference 13). NA, not applicable; ND, not determined.

Measurements of ACHE and CHE catalytic activities in soluble and membrane-associated fractions from tumor homogenates revealed variable levels of both enzymes, in the range of 100 to $1,000 \mathrm{nmol}$ acetylthiocholine and butyrylthio- choline hydrolyzed per minute per gram of tissue. There was no correlation between the level of soluble or membrane-associated enzyme activities and the extent of ACHEDNA and/or CHEDNA amplifications (Table I). However, the CHE activi- 


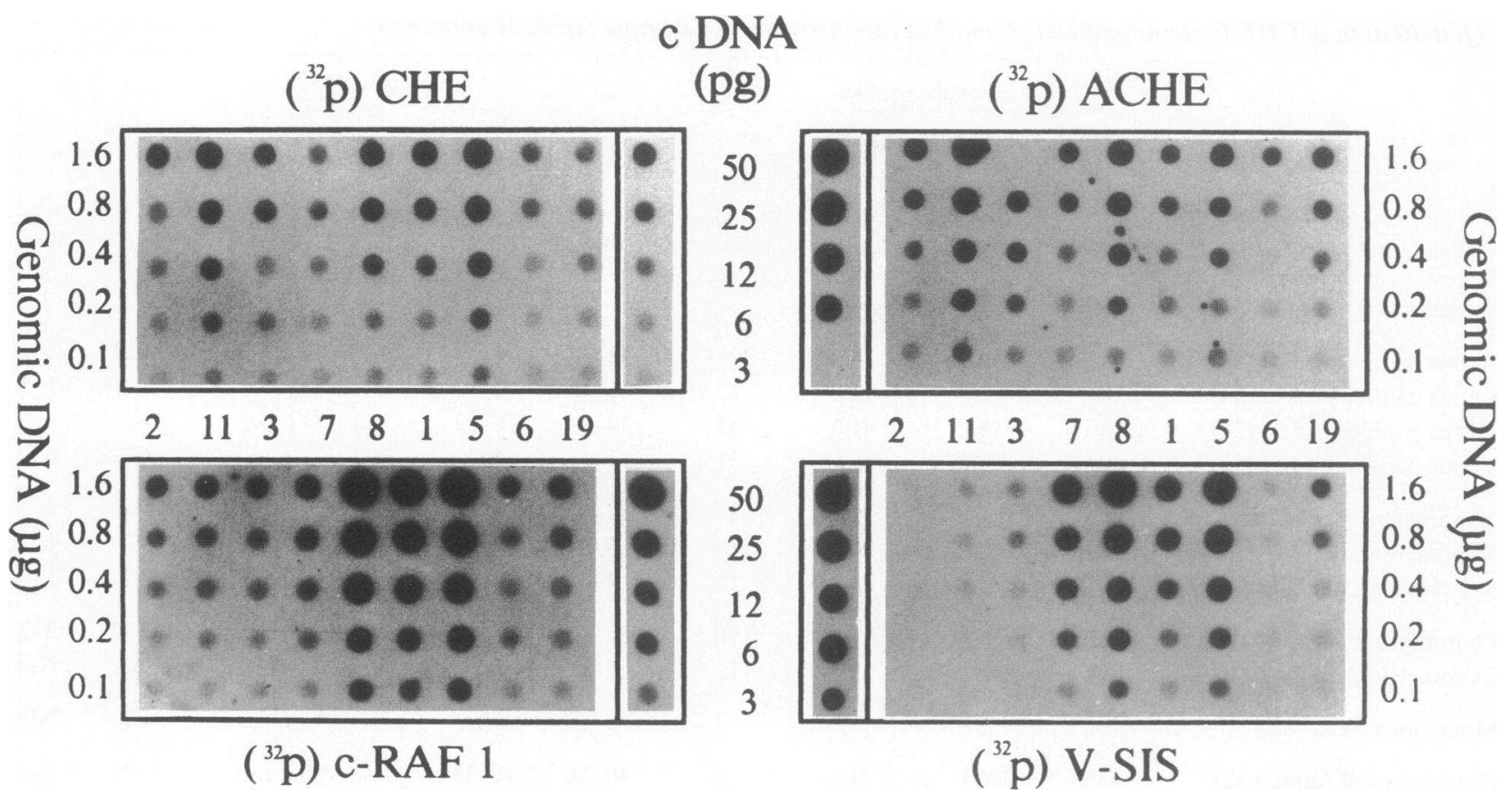

Figure 3. Co-amplification of the ACHE and CHE genes with RAFI and v-sis oncogenes demonstrated by dot-blot hybridization. Quantification of the ACHE and CHE genes coamplification in DNA samples from malignant and benign tumor tissues (Table I) was performed by dotblot DNA hybridizations followed by optical densitometry of blot autoradiograms in comparison with the purified CHEcDNA and ACHEcDNA inserts as detailed elsewhere $(8,9)$. Parallel blots were hybridized with DNA probes for the oncogenes c-rafi, (Amersham) and $\mathrm{v}$-sis (gratefully received from Opher Gileadi). Blots presented include series of twofold dilutions of microgram quantities of genomic DNA preparations. Note the amplified signals in several of the examined samples and the coamplification of the c-rafi and v-sis oncogenes in part, although not all of these samples. Representative calibration blots with picogram quantities of the relevant purified cDNA inserts are included (center).

ties in tumor homogenates could be accounted for by residual blood contaminations, capable of contributing CHE activities in the range of several micromoles per minute per milliliter (22). Similarly, residual erythrocyte contaminations could explain the measured ACHE activities. Therefore, the question whether the amplified ACHEDNA and CHEDNA sequences were expressed as active hydrolytic enzymes in the tumor tissues could not be resolved by enzyme activity measurements.

The presence of CHEmRNA transcripts in the ovarian tumors was first pursued by RNA blot hybridization. In spite of some mRNA degradation in the tumor biopsies this analysis revealed, in three of the tumors bearing amplified CHEDNA, significantly enhanced labeling of a full-length $2.4 \mathrm{~kb}$ CHEmRNA relative to that observed in normal ovarian tissue (13) and in other normal developing tissues (Fig. $4 A$ ). The G,C-rich ACHEcDNA probe (1) gave inconclusive results. However, when poly(A)+RNA from several such ovarian tumors was microinjected into groups of 30 Xenopus oocytes, it directed the synthesis of ACHE activity, sensitive to the selective inhibitor BW284C51 (Fig. 4 B). The level of induced ACHE activity was about twice as high as that previously measured for brain ACHEmRNA $(15,20)$. Because of the variability between different oocyte translation experiments (20\% deviation between measures) and the small difference between the activities measured in the absence and presence of the CHE-specific inhibitor iso-OMPA, we were unable to determine whether active $\mathrm{CHE}$ was synthesized as well (Fig. $4 \mathrm{~B}$ ). Therefore, RNA blot hybridizations and Xenopus oocyte mi- croinjections could demonstrate translatable and intact ACHEmRNA and CHEmRNA, respectively.

The presence and expression of the mRNA transcripts produced from the amplified ACHE and CHE genes was further assessed in frozen tissue sections, where the existence of mRNA transcripts could be demonstrated by in situ hybridization, their protein product by immunocytochemical staining with monoclonal anti-ACHE antibodies (23), which crossreact with $\mathrm{CHE}$ (18), and enzymatic activity by cytochemical staining with acetylthiocholine complexes (19). When consecutive sections from single tumors were subjected to these three analyses, tumor foci in corresponding positions were revealed in which the ACHE and CHE genes were highly expressed, with clear colocalized labeling by the three techniques (Fig. 5). These foci were limited to malignant tumors bearing the amplified ACHE and CHE genes, and were not observed in any of the other tissue types that were examined. Labeled areas were localized deep within the tumor tissue and contained primarily small, rapidly dividing cells. Semiquantitative analysis of the in situ hybridization results demonstrated that only $8-12 \%$ of the examined areas were significantly labeled with the CHEcDNA probe $\left(100 \pm 15\right.$ grains/ $100 \mu \mathrm{m}^{2}$ as compared with $6 \pm 3$ grains $/ 100 \mu \mathrm{m}^{2}$ in unlabeled areas [ $n=25$ fields]). Parallel analysis with the ACHEcDNA probe on sequential sections from the same tumors revealed that $9-14 \%$ of the analyzed cells were significantly labeled $\left(75 \pm 14\right.$ grains $/ 100 \mu \mathrm{m}^{2}$ over $7 \pm 2$ grains $/ 100 \mu \mathrm{m}^{2}$ in unlabeled areas [ $n=25$ fields]). Labeling was sensitive to RNase treatment and reproducibly focal in nature. 


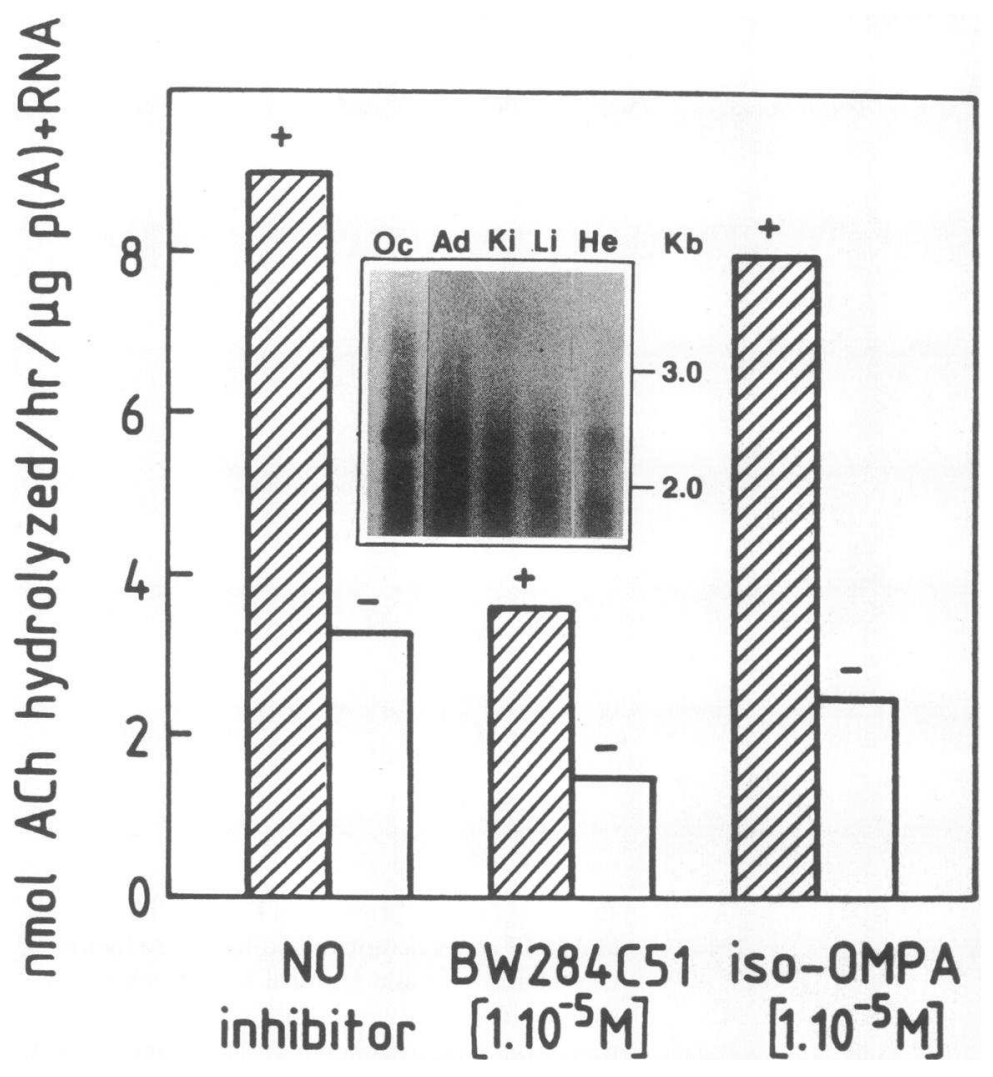

Figure 4. RNA blot hybridization demonstrates expression of full-length CHEmRNA and Xenopus oocyte microinjection reveals translatable ACHEmRNA in ovarian carcinoma. 50-ng samples of poly(A)+RNA from the same primary tumor referred to under $A$ were injected into Xenopus laevis oocytes and the resultant acetylcholine ACh hydrolyzing activities $(+)$ were measured as detailed elsewhere $(15$, 20). Barth-medium injected oocytes served as controls (-). The selective inhibitors 1,5-bis (4-allyldimethylammoniumphenyl)-pentan-3-one dibromide (BW284C51) and tetraisopropylpyrophosphoramide (iso-OMPA) were both employed in final concentrations of 1.10-5 $\mathrm{M}$ to specifically block the activities of ACHE and CHE, respectively. Note the intensive production of ACHE activity in the tumor mRNA-injected oocytes (For comparison, fetal brain mRNA induces $1.4 \mathrm{nmol}$ ACh hydrolyzed/ $\mu \mathrm{g}$ RNA [15]). (Inset) 10- $\mu \mathrm{g} \mathrm{sam-}$ ples of poly(A)+RNA from a representative ovarian carcinoma tumor (Oc, No. 8 in Table I and Figs. 1 and 2) and from fetal human adrenal $(A d)$, kidney $(K i)$, liver $(L i)$, and Heart ( $\mathrm{He}$ ) (17 wk gestation) were subjected to gel electrophoresis and RNA blot hybridization with $\left.{ }^{32} \mathrm{P}\right] \mathrm{CHECDNA}$ as previously detailed (2). Repeated hybridization of the same blot with a non-cross-reactive cDNA probe, termed TH 14, revealed low intensity signals in all lanes (not shown), implying that the intensified labeling of $2.4 \mathrm{~kb}$ CHEmRNA in the tumor tissue was specific and was not due to RNA overloading. Ribosomal RNA (28S, $5 \mathrm{~kb}$, and $18 \mathrm{~S}, 2 \mathrm{~kb}$ ) served for size markers. Exposure was for $5 \mathrm{~d}$ at $-70^{\circ} \mathrm{C}$ with an intensifying screen. RNA blot hybridization of poly(A)+RNA from normal ovary revealed no signal at all (13).

\section{Discussion}

Several mechanisms have been proposed to account for gene amplification in mammalian genomes. One of these is the insertion and subsequent amplification of a retroviral DNA containing host sequences (24), perhaps in the form of a processed cDNA. However, the amplified CHE genes in ovarian tumors appear to contain introns and are not processed. A second mechanism that has been proposed is the "incidental" amplification of a gene residing close to an amplifiable protooncogene. The core amplification unit including the nmyc protooncogene is, for example, $3,000 \mathrm{~kb}$ in size (25), and the HSTF1 transforming factor, which maps to chromosome band $11 \mathrm{q} 13$, co-amplifies with the INT2 gene in multiple cancerous cells (26). A third possibility is that our amplified sequences contain internal origins of replication, enabling their independent amplification under certain circumstances, similar to the mechanism proposed for the developmentally regulated amplification of the chorion gene clusters in Drosophila (27). It is unclear which of the two latter mechanisms, if any, might be applicable to the amplification of the CHE and ACHE genes in ovarian carcinomas. Furthermore, it is unclear whether these genes are subject to linked but independent amplification events, or coamplify as a single unit. The observation that restriction fragments of similar lengths from both genes hybridize with both the non-cross-hybridizing cDNA probes could reflect shared genomic sequences and argues for coamplification. Nonetheless, and unlike the HSTF1/INT2 example, there does not appear to be a direct 1:1 correlation be- tween the number of copies of the two genes in various tumors. Molecular cloning and further chromosomal mapping (28) of the amplified ACHEDNA and CHEDNA in ovarian tumors and their flanking sequences will be required to clarify this issue.

All of the tumors which displayed extensive amplification in the c-rafi, v-sis, and c-fes oncogenes also had high levels of $\mathrm{CHE} / \mathrm{ACHE}$ genes and high ratios between copy numbers of CHE:ACHE sequences. Other tumor samples had high extents of CHE/ACHE genes but not of oncogenes, perhaps indicating that the CHE/ACHE genes are amplified earlier in tumorigenesis than the oncogenes and that $\mathrm{CHE}$ gene amplification precedes that of ACHE. Interestingly, the CHE gene is expressed earlier than ACHE also in embryogenesis (29).

RNA blot hybridization, immunochemical and cytochemical staining, and Xenopus oocyte microinjection with tumor RNA all demonstrated that the amplified CHE and ACHE genes are expressed within tumor tissues to yield their catalytically active enzyme products. Regarding the amplified CHE genes, we could show transcription products but remained uncertain as to whether these were translationally active. It is not yet known which promoter directs the expression of the ACHE and CHE genes in these tumors or why they are only expressed in a minor fraction of the cells. A large body of information suggests that $\mathrm{ACHE}$ and/or $\mathrm{CHE}$ activities are transiently expressed during cell growth and/or proliferation in multiple systems $(5,7,10,16)$. If indeed this reflects a growth-related role for these enzymes, amplified and expressed ACHE and CHE genes could confer a selective advantage in localized areas of rapidly growing cells within the tumor tissue. This 

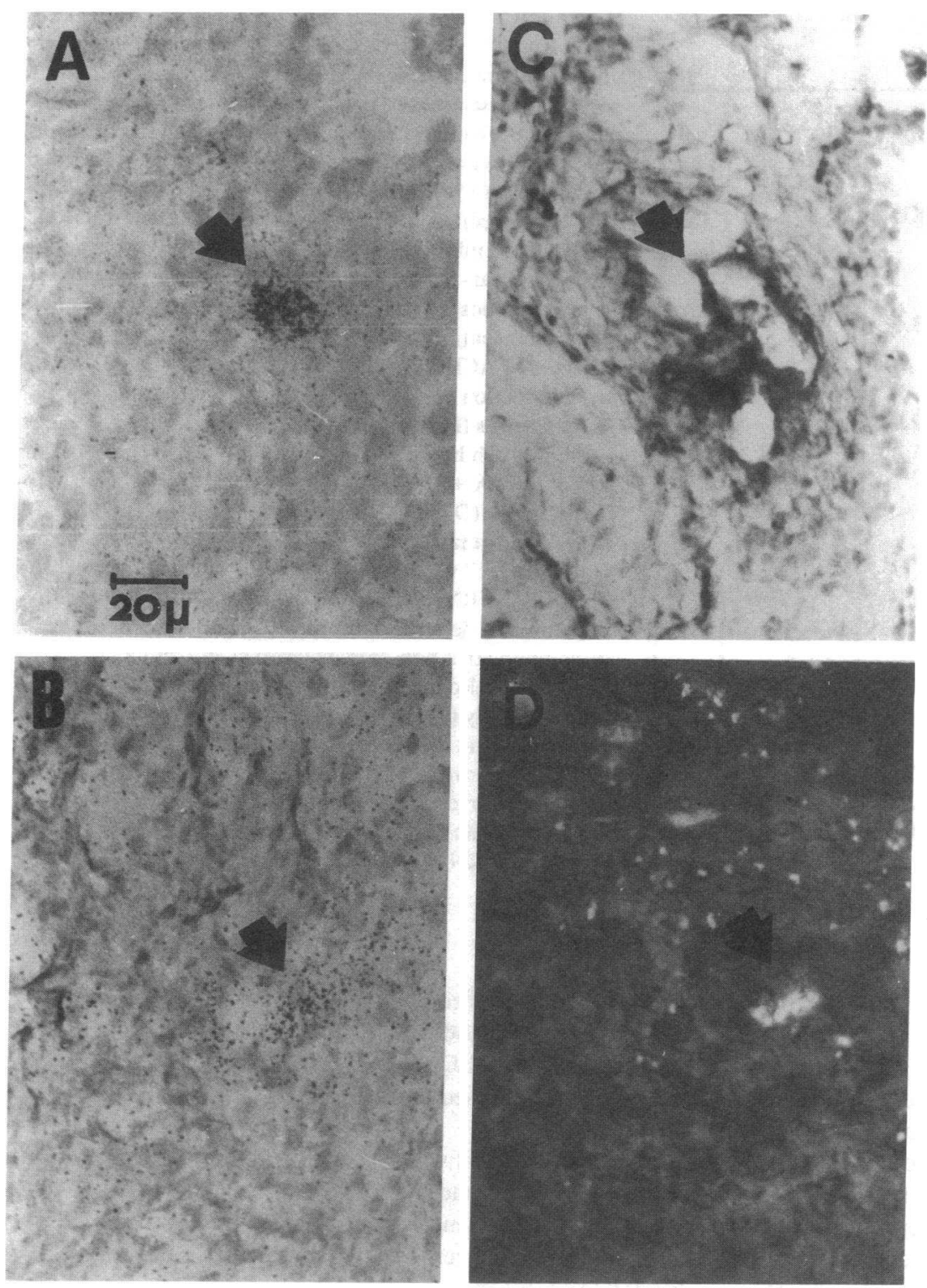

Figure 5. Focal expression of the amplified ACHE and CHE genes demonstrated by in situ hybridization and immunochemical and cytochemical staining. Consecutive $10-\mu \mathrm{m}$ thick cryostat sections from a representative ovarian tumor (No. 3, see Table I and Figs. 1 and 2) were subjected to in situ hybridization with $\left[{ }^{35} \mathrm{~S}\right] \mathrm{CHECDNA}(A)$ or $\left[{ }^{35} \mathrm{~S}\right] \mathrm{ACHECDNA}(B)$, cytochemical staining with acetylthiocholine complexes $(C)$ or fluorescence labeling with the AE-2 monoclonal antibodies to $\operatorname{ACHE}(D)$, all performed as previously detailed $(13,23,18,19)$. Hematoxylin-eosin served for counterstain. The sections presented were $100 \mu \mathrm{m}$ apart. Note $(a)$ the corresponding central position of the four types of labeling within the tumor tissue; $(b)$ the focal nature of the labeled cells and $(c)$ the presence of small rapidly dividing cells at the center of the labeled area. notion is supported by the recent finding that the ACHE and CHE genes are coamplified in leukemias (9). Furthermore, enhanced and altered modes of expression of cholinesterases were biochemically demonstrated in various brain tumors (11, 30 ) as well as in the sera of patients suffering from different types of carcinomas (22). These could potentially reflect similar coamplification events, suggesting that the ACHE and CHE genes amplification might be correlated with the etiology of the disease, in analogy with the NEU oncogene amplification, which is related with relapse and survival in breast cancer (31).

The possibility should be considered that ACHE and CHE gene amplifications in ovarian tumors might be associated with the common subacute exposure to organophosphorous (OP) insecticides, inhibitors of cholinesterases (32). Gene amplification in DDT-exposed insects (33) or in tumors exposed to chemotherapeutic (34) or antibiotic (35) drugs has been correlated with the use of such toxic compounds. An in loco amplification of a defective $\mathrm{CHE}$ gene was recently found on the long arm of chromosome 3 in a family exposed to chronic subacute doses of the organophosphorous insecticide methylparathion (8). Also, organophosphorous pesticides induce chromosome damage in cultured human cells (36) as well as in workers exposed to these poisons (37). In mice, administration of acetylcholinesterase protects against organophosphate poisoning (36). Several developmental-related roles have been suggested for cholinesterases over the years (reviewed in reference 6). The amplification of their corresponding genes could hence be indicative of the importance of the fine tuning of cholinergic signaling in cellular differentiation in multiple biosystems. It would be important to find out whether the continuous low-level exposure to common agricultural insecticides might disrupt these processes and support the above described gene amplifications; the correlation between all these phenomena will have to be further examined to assess the abundance of common ACHE and CHE gene amplification in various tumor types, to establish the origin and mecha- 
nism of these amplification events, and to evaluate their role in tumorigenesis.

\section{Acknowledgments}

We are grateful to Drs. Opher Gileadi for the oncogene DNA probes, B. P. Doctor (Washington, DC) for the monoclonal antibodies against ACHE and Alan H. Mehler (Dept. of Biochemistry, Howard University, Washington, DC), for critically reviewing this manuscript.

Supported by the Research Fund at the Edith Wolfson Medical Center (to Dr. Zakut), by contract DAMD-17-87-7169 (to Dr. Soreq), by the Israel Cancer Research Fund (to Dr. Malinger), and by the Chief Scientist at the Israeli Health Ministry (to Dr. Ayalon). Mr. Ehrlich has a Golda Meir predoctoral fellowship.

\section{References}

1. Soreq, H., and C. A. Prody. 1989. Sequence similarities between human acetylcholinesterase and related proteins: putative implications for therapy of anticholinesterase intoxication. In Computer-assisted Modeling of Receptor-Ligand Interactions, Theoretic Aspects and Application to Drug Design. A. Golombek and R. Rein, editors. Alan R. Liss, New York. 347-359.

2. Prody, C. A., A. Gnatt, D. Zevin-Sonkin, O. Goldberg, and H. Soreq. 1987. Isolation and characterization of full-length cDNA clones coding for cholinesterase from fetal human tissues. Proc. Natl. Acad. Sci. USA. 84:3555-3558.

3. McTiernan, C., S. Adkins, A. Chatonnet, T. A. Vaughan, C. F. Bartels, M. Kott, T. L. Rosenberry, B. LaDu, and O. Lockridge. 1987. Brain cDNA clone for human cholinesterase. Proc. Natl. Acad. Sci. USA. 84:6682-6686.

4. Toutant, J. P., and J. Massoulie. 1988. Cholinesterase II-tissue and cellular distribution of the molecular forms and their physiological regulations. In The Cholinergic Synapse. V. P. Whittaker, editor. 86:167-224.

5. Seidman, S., and H. Soreq. 1990. Co-injection of Xenopus oocytes with cDNA-produced and native mRNAs: a molecular biological approach to the tissue specific processing of human cholinesterases Int. Rev. Neurobiol. 32:107-139.

6. Rakonczay, Z., and S. Brimijoin. 1988. Biochemistry and pathophysiology of the molecular forms of cholinesterases. In Subcellular Biochemistry. J. R. Harris, editor. Plenum Press, New York. 12:355378.

7. Layer, P. G., R. Alber, and O. Sporns. 1987. Quantitative development and molecular forms of acetyl- and butyrylcholinesterase during morphogenesis and synaptogenesis of chick brain and retina. $J$. Neurochem. 49:175-182.

8. Prody, C. A., P. Dreyfus, R. Zamir, H. Zakut, and H. Soreq. 1989. De novo amplification within a "silent" human cholinesterase gene in a family subjected to prolonged exposure to organophosphorous insecticides. Proc. Natl. Acad. Sci. USA. 86:690-694.

9. Lapidot-Lifson, Y., C. A. Prody, D. Ginzberg, D. Meytes, H. Zakut, and H. Soreq. 1989. Co-amplification of human acetylcholinesterase and butyrylcholinesterase genes in blood cells. Correlation with various leukemias and abnormal megakaryocytopoiesis. Proc. Natl. Acad. Sci. USA. 86:4715-4719.

10. Drews, E. 1975. Cholinesterase in embryonic development. Prog. Histochem. Cytochem. 7:1-52.

11. Razon, N., H. Soreq, E. Roth, A. D. Bartal, and I. Silman. 1984. Characterization of activities and forms of cholinesterases in human primary brain tumors. Exp. Neurol. 84:681-695.

12. Slotman, B. J., and B. R. Rao. 1988. Ovarian cancer (review).
Etiology, diagnosis, prognosis, surgery, radiotherapy, hemotherapy and endocrine therapy. Anticancer Res. 8:417-434.

13. Soreq, H., G. Malinger, and H. Zakut. 1987. Expression of cholinesterase genes in developing human oocytes revealed by in situ hybridization. Hum. Reprod. 2:689-693.

14. Malinger, G., H. Zakut, and H. Soreq. 1989. Cholinoceptive properties of human primordial, pre-antral and antral oocytes: In situ hybridization and biochemical evidence for expression of cholinesterase genes. J. Mol. Neurosci. 1:77-84.

15. Soreq, H., D. Zevin-Sonkin, and N. Razon. 1984. Expression of cholinesterase gene(s) in human brain tissues: translational evidence for multiple mRNA species. (Eur. Mol. Biol. Organ.) EMBO J. 3:1371-1375.

16. Soreq, H., and A. Gnatt. 1987. Molecular biological search for human genes encoding cholinesterases. Mol. Neurobiol. 1:47-80.

17. McGuire, M. C., C. P. Nogueira, C. F. Bartels, H. Lightstone, A. Hajra, A. F. L. Van der Spek, O. Lockridge, and B. LaDu. 1989. Identification of the structural mutation responsible for the dibucaine-resistant (atypical) variant form of human serum cholinesterase. Proc. Natl. Acad. Sci. USA. 86:953-957.

18. Dreyfus, P., D. Zevin-Sonkin, S. Seidman, C. A. Prody, R. Zisling, H. Zakut, and H. Soreq. 1988. Cross-homologies and structural differences between human cholinesterases revealed by antibodies against cDNA-produced butyrylcholinesterase peptides. $J$. Neurochem. 51:1858-1867.

19. Dreyfus, P. A., S. Seidman, M. Pincon-Raymond, M. Murawsky, F. Rieger, E. Schejter, H. Zakut, and H. Soreq. 1989. Tissue-specific processing and polarized compartmentalization of clone-produced cholinesterase in microinjected Xenopus oocytes. Mol. Cell. Neurobiol. 9:323-341.

20. Soreq, H., S. Seidman, P. A. Dreyfus, D. Zevin-Sonkin, and H. Zakut. 1989. Expression and tissue-specific assembly of cloned human butyrylcholinesterase in microinjected Xenopus laevis oocytes. J. Biol. Chem. 264:10608-10613.

21. Chatonnet, A., and O. Lockridge. 1989. Comparison of butyrylcholinesterase and acetylcholinesterase. Biochem. J. 260:625-634.

22. Zakut, H., L. Even, S. Birkenfeld, G. Malinger, R. Zisling, and H. Soreq. 1988. Modified properties of serum cholinesterase in primary carcinomas. Cancer (Phila.). 61:727-737.

23. Mollgard, K., K. M. Dziegielewska, N. R. Saunders, H. Zakut, and $\mathrm{H}$. Soreq. 1988. Synthesis and localization of plasma proteins in the developing human brain: integrity of the fetal blood-brain barrier to endogenous proteins of hepatic origin. Dev. Biol. 128:207-221.

24. Bishop, J. M. 1987. The molecular genetics of cancer. Science (Wash. DC). 235:305-311.

25. Kohl, N. E., N. Kanda, R. R. Schreck, G. Bruns, S. A. Latt, F. Gilbert, and F. W. Alt. 1983. Transposition and amplification of oncogene-related sequences in human neuroblastoma. Cell. 35:359-367.

26. Yoshida, M. C., M. Wada, H. Satoh, T. Yoshida, H. Sakamoto, K. Miyagawa, J. Yokota, T. Koda, M. Kakinuma, T. Sugimura, and M. Terada. 1988. Human HSPI (HSPF1) gene maps to chromosome band $11 \mathrm{q} 13$ and co-amplifies with the INT2 genes in human cancer. Proc. Natl. Acad. Sci. USA. 85:4861-4864.

27. Spradling, A. 1987. Results and problems in cell differentiation. In Structure and Function of Eukaryotic Chromosomes. Vol. 14. W. Hennig, editor. Springer-Verlag, Berlin/Heidelberg. 200-212.

28. Soreq, H., R. Zamir, D. Zevin-Sonkin, and H. Zakut. 1987. Human cholinesterase genes localized by hybridization to chromosomes 3 and 16. Hum. Genet. 77:325-328.

29. Layer, P. G., and O. Sporns. 1987. Spatiotemporal relationship of embryonic cholinesterases with cell proliferation in chicken brain and eye. Proc. Natl. Acad. Sci. USA. 84:284-288.

30. Gnatt, A., C. A. Prody, R. Zamir, J. Lieman-Hurwitz, H. Zakut, and $H$. Soreq. 1990. Expression of alternatively terminated unusual CHEmRNA transcripts mapping to chromosome 3q26-ter in nervous system tumors. Cancer Res. 50:1983-1987.

31. Slamon, D. J., G. M. Clark, S. G. Wong, W. J. Levin, A. 
Ullrich, and W. L. McGuire. 1987. Human breast cancer: correlation of relapse and survival with amplification of the HER-2/neu oncogene. Science (Wash. DC). 235:177-182, 1987.

32. U. N. Security Council. 1984. Report of specialists appointed by the Secretary General, Paper 5/16433.

33. Mouches, C., N. Pasteur, J. B. Berge, O. Hyrien, M. Raymond, B. R. De Saint Vincent, M. Silvestri, and G. P. Georghiou. 1986. Amplification of an esterase gene is responsible for insecticide resistence in a California Culex mosquito. Science (Wash. DC). 233:778780.

34. Schimke, R. T. 1984. Gene amplication in cultured animal cells. Cell. 37:705-713.

35. Scotto, K. W., J. L. Biedler, and P. W. Melera. 1986. Amplifi- cation and expression of genes associated with multidrug resistance in mammalian cells. Science (Wash. DC). 232:751-755.

36. Ahmed, F., R. Hart, and N. Lewis. 1977. Pesticide induced DNA damage and its repair in cultured human cells. Mutat. Res. 42:161-174.

37. Kiraly, J., I. Szentesi, M. Ruzicska, and A. Czeizel. 1979. Chromosome studies in workers producing organophosphate insecticides. Arch. Environ. Contamin. Toxicol. 8:309-319.

38. Raveh, L., Y. Ashani, D. Levi, D. De La Hoz, A. D. Wolfe, and B. P. Doctor. 1989. Acetylcholinesterase prophylaxis against organophosphate poisoning. Quantitative correlation between protection and blood-enzyme level in mice. Biochem. Pharmacol. 38:529-534. 